\title{
KLASIFIKASI DESA/KELURAHAN DI KABUPATEN GIANYAR: EKSTRAKSI DAN KLASIFIKASI POTENSI WISATA
}

\author{
Mirah P Handayani \\ Program Studi Matematika - FMIPA Universitas Udayana \\ Kampus Jimbaran - Badung 80361 \\ E-mail: putumirah24@gmail.com \\ Putu Suciptawati \\ Program Studi Matematika - FMIPA Universitas Udayana \\ Kampus Jimbaran - Badung 80361 \\ E-mail: suciptawati@unud.ac.id \\ Trisna Darmayanti \\ Program Studi Teknologi Pangan - FTP Universitas Udayana \\ Kampus Jimbaran - Badung 80361 \\ E-mail: trisnadarmayanti@unud.ac.id \\ Eka N Kencana* \\ Pusat Unggulan Pariwisata Universitas Udayana - Kampus Sudirman \\ Program Studi Matematika - Kampus Jimbaran - Badung 80361 \\ E-mail: i.putu.enk@unud.ac.id \\ *Penulis Korespondensi
}

\begin{abstract}
Tourism potential is one of the primary sources of destination development. Generally, there are three types of tourism potential that form tourist attractions. These potentials are (a) natural potential, (b) socio-cultural potential, and (b) artificial potential. Regarding destination sustainability, the uniqueness of villages' potentials is the primary factor to consider. This paper aims to identify the tourism potential of 70 villages in Gianyar Regency, Bali Province that spread over seven districts. The primary data collected from 170 respondents from August to September 2020, proportionally distributed over 70 villages. They were asked their opinion about the village's potential to be developed as a tourist village. The factors extracted from village tourism potential indicators were obtained by factor analysis and is used to form a tourism village cluster. The clustering showed three village groups, each consisting of 13,24 , and 33 villages.
\end{abstract}

Keywords: classification, cultural tourism, factor analysis, village tourism 


\section{Pendahuluan}

Sebagai salah satu sentra kepariwisataan Bali, struktur perekonomian Kabupaten Gianyar sangat mirip dengan struktur perekonomian Bali yang ditopang oleh dua lapangan usaha dominan yaitu Pertanian, Kehutanan, dan Perikanan serta lapangan usaha Penyediaan Akomodasi dan Makan Minum. Pada tahun 2019, dari total nilai Produk Domestik Regional Bruto (PDRB) Kabupaten Gianyar sejumlah 28 581,34 milyar rupiah, kedua lapangan usaha ini memberikan kontribusi masingmasing sebesar 12,01 persen dan 26,02 persen (atas dasar harga berlaku/adhb 2019) (BPS Kabupaten Gianyar, 2020). Mengacu kepada dominannya peran lapangan usaha Penyediaan Akomodasi dan Makan Minum pada perekonomian kabupaten, tidak mengherankan pariwisata menjadi primadona tidak hanya di tingkat kabupaten, pun di tingkat lebih rendah seperti kecamatan atau desa.

Pada level provinsi, terdapat perbedaan kinerja yang menonjol antarkabupaten atau kota. Data dari Dinas Pariwisata Provinsi Bali (2020) menunjukkan rentang data kunjungan wisatawan yang sangat lebar sebesar 4,7 juta orang. Jumlah kunjungan tertinggi pada tahun 2019 tercatat ke Kabupaten Gianyar sebesar 5 juta orang dan jumlah kunjungan terendah tercatat ke Kabupaten Jembrana sebesar 300 ribu orang (gambar 1).

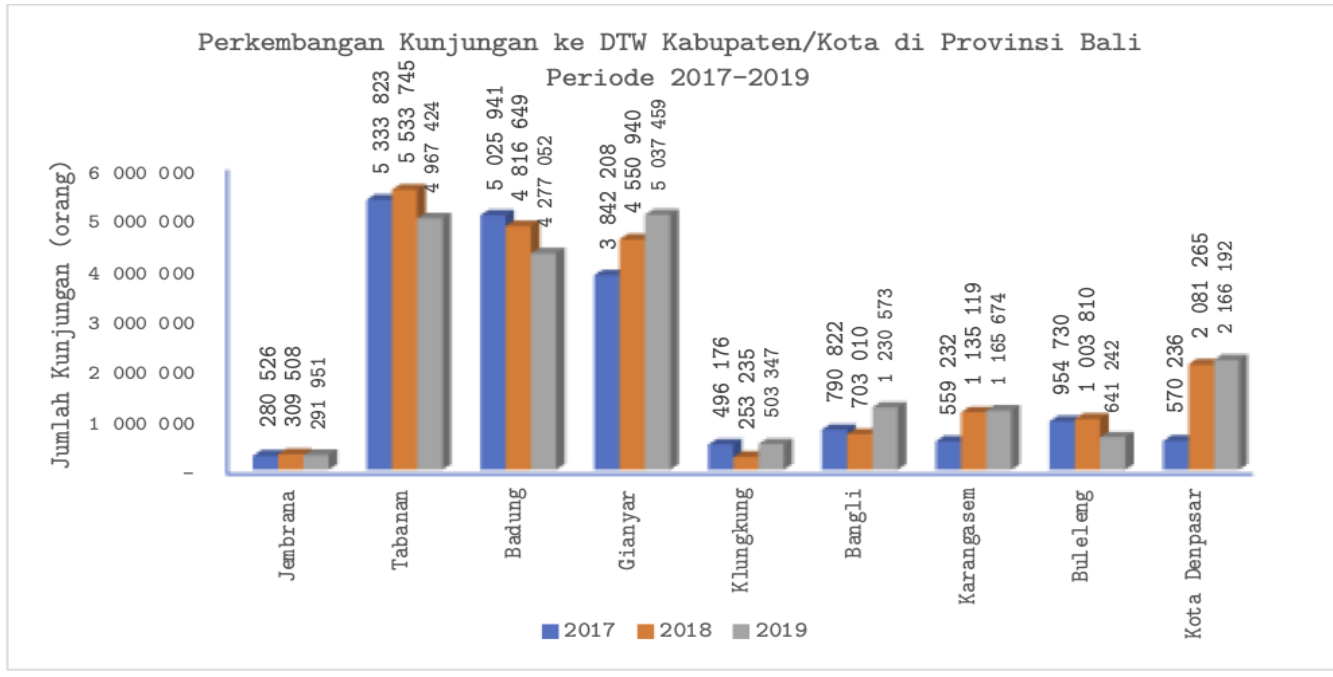

Gambar 1. Perkembangan Kunjungan ke Daya Tarik Wisata, Periode 2017 - 2019 
Gambar 1 memperlihatkan pada periode 2017-2019 Kabupaten Gianyar memiliki kinerja terbaik mengenai total kunjungan wisatawan. Pada periode ini Gianyar mengalami pertumbuhan kunjungan positif. Menurut Keputusan Bupati Gianyar Nomor 429/E-02/HK/2017 tentang Penetapan Desa Wisata di Kabupaten Gianyar, tercatat ada 19 desa wisata dan 23 daya tarik wisata (DTW) yang tersebar di seluruh kecamatan. Mencermati besarnya ekspektasi masyarakat tentang dampak pariwisata pada perekonomian mereka, tidak mengherankan munculnya euforia masing-masing desa di Gianyar untuk 'mendeklarasikan' potensi daya tarik yang dimiliki layak dijadikan DTW.

Sayangnya euforia ini tidak sejalan dengan fakta empirik mengenai kunjungan wisatawan ke DTW. Sebagian besar pengunjung DTW di Kabupaten Gianyar hanya memusat di tiga DTW yaitu (a) Mandala Suci Wanara Wana, lebih populer dengan sebutan 'The Monkey Forest' yang berlokasi di Kecamatan Ubud; (b) Tirta Empul di Kecamatan Tampaksiring; dan (c) Air Terjun Tegenungan di Kecamatan Sukawati. Ketiga DTW ini pada tahun 2019 dikunjungi oleh sekitar 3 juta pengunjung (60 persen dari total kunjungan). Gambar 2 menunjukkan 10 besar DTW dengan pengunjung terbanyak di Kabupaten Gianyar.

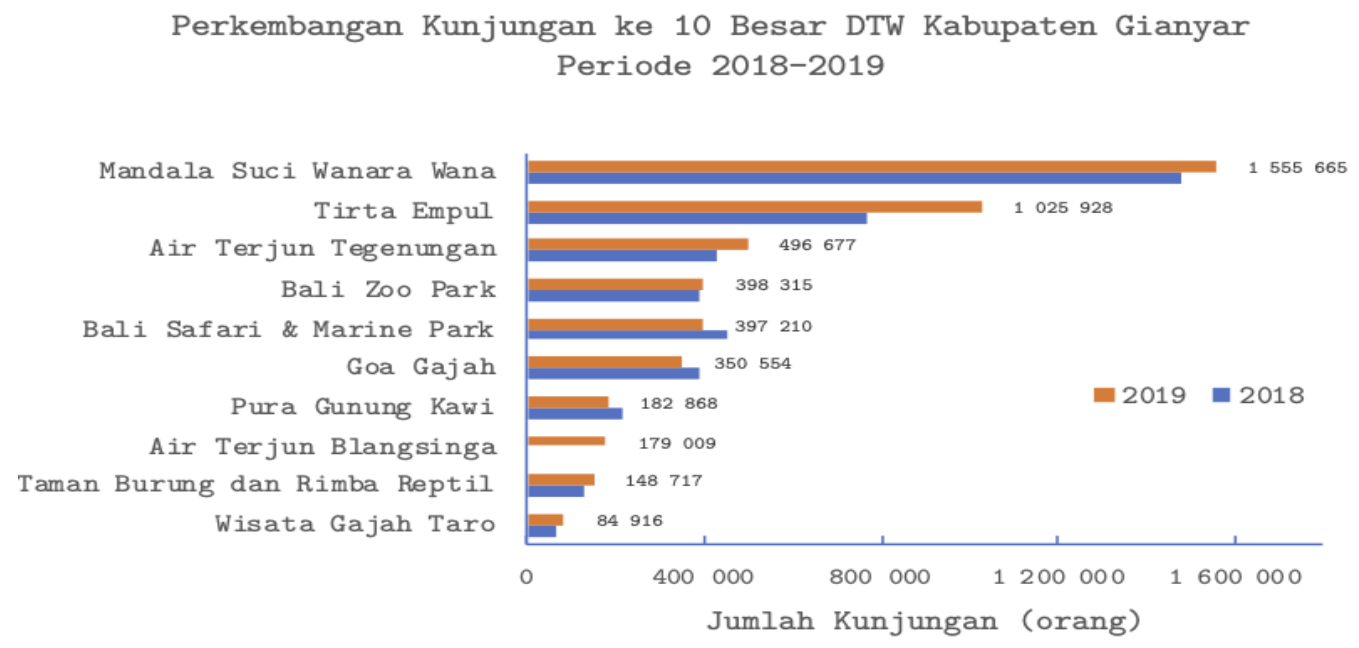

Gambar 2. Perkembangan Kunjungan ke 10 Besar DTW Kabupaten Gianyar, Periode $2018-2019$ 
Secara empirik data kunjungan ke DTW di Kabupaten Gianyar mengindikasikan bahwa euforia masyarakat dan/atau pemerintah untuk mendeklarasikan desa sebagai DTW semata belum menjadi jaminan dalam meningkatkan kunjungan wisatawan. Sebagian besar DTW di kabupaten ini rata-rata hanya dikunjungi oleh kurang dari 17000 pengunjung per tahun, kurang lebih 45 orang per hari. Mencermati fakta ini, kebijakan dan strategi pembentukan dan pengembangan desa wisata di Kabupaten Gianyar perlu dikaji ulang.

Tidak bisa dipungkiri bahwa keunikan sumber daya alam serta sosial budaya masyarakat merupakan potensi untuk membangun desa sebagai DTW. Meski demikian, sangatlah penting memperhatikan potensi desa tetangga agar daya tarik yang dimunculkan bersifat unik sehingga antar-DTW tidak terjadi persaingan yang tidak sehat. Tulisan ini ditujukan untuk mengidentifikasi potensi daya tarik alam, potensi sosial-budaya masyarakat, serta sarana dan prasarana pendukung yang bermanfaat dalam membangun atau mengembangkan desa-desa di Kabupaten Gianyar sebagai DTW. Hasil identifikasi potensi selanjutnya digunakan sebagai informasi dalam melakukan klasterisasi desa sebagai daya tarik wisata.

\section{Metodelogi}

Terkait dengan tujuan artikel ini, pendekatan kuantitatif digunakan. Menurut Creswell (2009), pendekatan kuantitatif pada riset dicirikan digunakannya sejumlah variabel terukur, umumnya diperoleh melalui instrumen pengukur, serta pengambilan inferensia dilandasi oleh teknik atau metode Statistika. Pada artikel ini, data diperoleh dengan merancang instrumen pengukur berupa kuesioner. Item-item pernyataan disusun menggunakan skala Likert berderajat lima yang diukur pada skala ordinal, yang sebelumnya telah diuji validitasnya pada tahap pra-riset dengan mendistribusikan kepada 20 orang penduduk Kelurahan Ubud dan 15 orang penduduk dari Desa Buahan Kaja. 
Kuesioner yang telah diperiksa validitas item-item pengukur dan reliabilitas konsep yang dilibatkan, didistribusikan kepada 170 orang penduduk di 70 desa di Kabupaten Gianyar. Responden dipilih menggunakan teknik two-stages random proportional sampling agar pendapat masyarakat tentang potensi desanya sebagai DTW terwakili. Tahap pertama, persentase jumlah penduduk di masing-masing kecamatan terhadap total jumlah penduduk Kabupaten Gianyar pada tahun 2019 dihitung. Persentase ini digunakan untuk menentukan jumlah responden di setiap kecamatan. Tahap kedua, jumlah responden di masing-masing desa di setiap kecamatan ditentukan secara proporsional berdasarkan persentase penduduk desa terhadap penduduk kecamatan. Total sampel dari riset ini berukuran 170 orang, ditetapkan mencermati item pada kuesioner berjumlah 17 item dan menurut Hair et al. (2010) jumlah amatan per item sekurang-kurangnya 10 orang. Distribusi responden menurut kecamatan ditunjukkan pada Tabel 1.

Tabel 1. Distribusi dan Ukuran Sampel di Masing-masing Kecamatan

\begin{tabular}{llllll}
\hline No & Kecamatan & $\begin{array}{c}\text { Jumlah } \\
\text { Desa }\end{array}$ & $\begin{array}{c}\text { Jumlah } \\
\text { Penduduk } \\
\text { (ribu jiwa) }\end{array}$ & Persentase & $\begin{array}{c}\text { Ukuran } \\
\text { Sampel }\end{array}$ \\
\hline 1 & Sukawati & 12 & 125,5 & 24,5 & 42 \\
\hline 2 & Blahbatuh & 9 & 72,1 & 14,1 & 24 \\
\hline 3 & Gianyar & 17 & 94,6 & 18,5 & 31 \\
\hline 4 & Tampaksiring & 8 & 48,7 & 9,5 & 16 \\
\hline 5 & Ubud & 8 & 74,3 & 14,5 & 25 \\
\hline 6 & Tegallalang & 7 & 53,8 & 10,5 & 18 \\
\hline 7 & Payangan & 9 & 43,2 & 8,4 & 14 \\
\hline Kabupaten Gianyar & $\mathbf{7 0}$ & $\mathbf{5 1 2 , 2}$ & $\mathbf{1 0 0 , 0}$ & $\mathbf{1 7 0}$ \\
\hline
\end{tabular}

Sumber: BPS Kabupaten Gianyar (2020) 
Riset ini melibatkan 3 jenis potensi sumber daya desa yang diduga mendukung terbentuknya desa wisata yang berkualitas. Ketiga jenis sumber daya ini adalah (a) potensi alam desa; (b) potensi sosial budaya; dan (c) potensi penunjang. Ketiga jenis potensi ini diukur melalui 5 item, 5 item, dan 7 item pengukur. Menggunakan 17 item persepsi, dilakukan serangkaian analisis yang diringkas pada gambar 3. Tahapan analisis diawali dengan memeriksa validitas item-item pada setiap potensi. Item-item yang terbukti valid selanjutnya direduksi menjadi sejumlah komponen/faktor dengan Analisis Faktor. Seluruh faktor yang terekstraksi selanjutnya digunakan sebagai atribut dalam membangun klaster desa. Secara priori jumlah klaster yang akan dibentuk berjumlah 3 klaster; masing-masing menyatakan klaster desa yang telah berkembang, klaster desa yang sedang berkembang, dan klaster desa yang belum berkembang sebagai desa wisata.

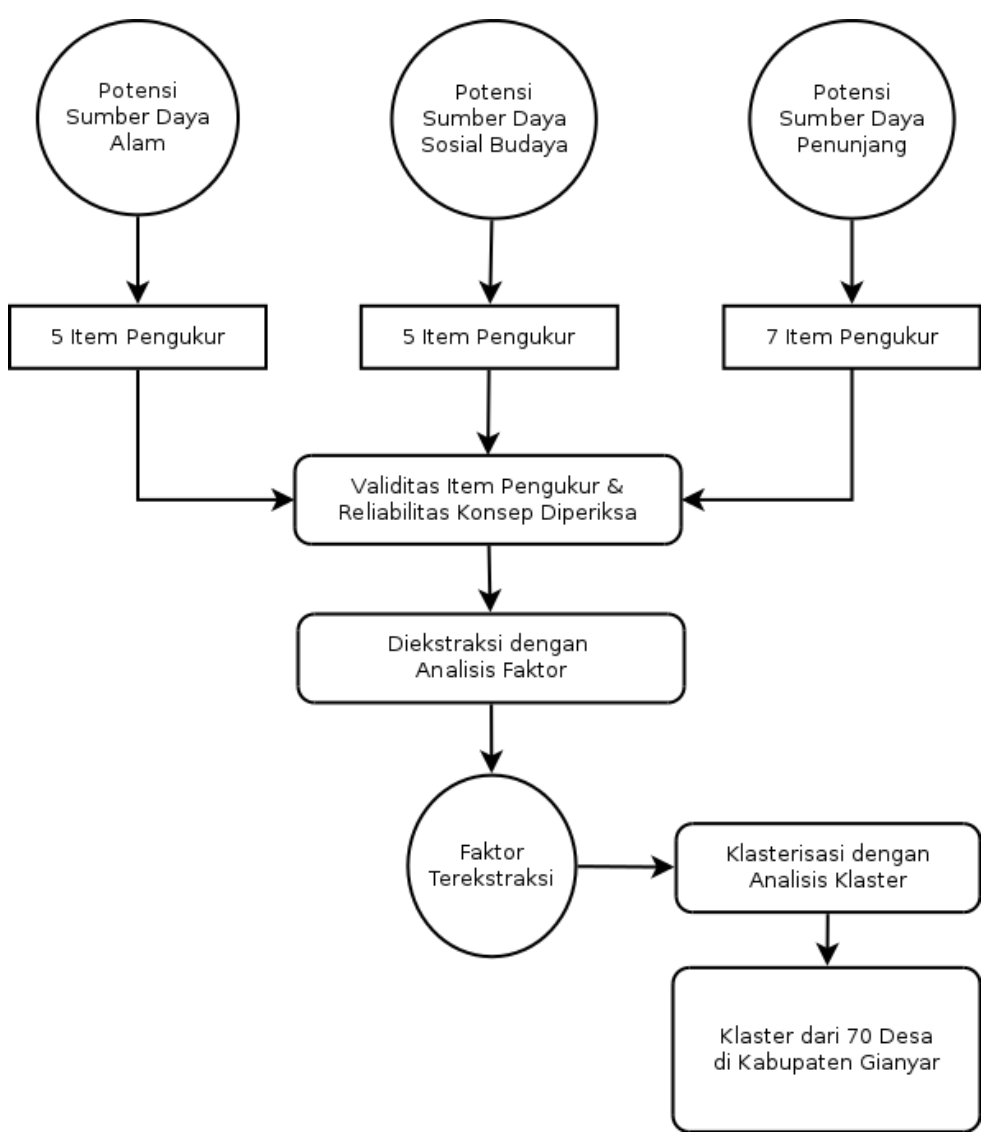

Gambar 3. Tahapan Analisis Data 


\section{Hasil-hasil Riset dan Diskusi}

\section{A. Validitas Item \& Reliabilitas Konsep}

Pada pengukuran tak langsung dari suatu konsep penelitian, validitas itemitem pengukur merupakan prasyarat penting agar inferensia statistik bermakna. Demikian pula dengan reliabilitas dari konsep yang diaplikasikan (Kencana et al., 2019). Sebuah item pengukur dinyatakan valid bila nilai korelasinya dengan total item pengukur lain pada konsep yang sama $(\rho)>0,30$ (Nunnally, 1975) dan suatu konsep dianggap layak digunakan bila koefisien $\alpha$ Cronbach > 0,60 (Hair et al., 2010). Hasil uji validitas dan reliabilitas menggunakan program SPSS ditunjukkan pada Tabel 2.

Tabel 2. Uji Validitas Item dan Reliabilitas Konsep Penelitian

\begin{tabular}{|c|c|c|c|}
\hline \multirow{2}{*}{ Konsep } & \multicolumn{3}{|c|}{ Item Pengukur } \\
\hline & Kode & Deskripsi & $\rho$ \\
\hline \multirow{5}{*}{ 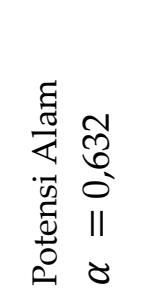 } & PA1 & Panorama desa & 0,607 \\
\hline & PA2 & Keunikan flora & 0,284 \\
\hline & PA3 & Keunikan fauna & 0,496 \\
\hline & PA4 & Keasrian desa & 0,495 \\
\hline & PA5 & Keunikan alam & 0,183 \\
\hline \multirow{5}{*}{ 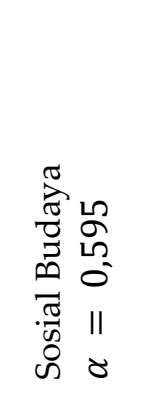 } & PSB1 & Situs purbakala & 0,072 \\
\hline & PSB2 & $\begin{array}{l}\text { Pura sebagai daya } \\
\text { tarik wisata }\end{array}$ & 0,421 \\
\hline & PSB3 & Ritual keagamaan & 0,186 \\
\hline & PSB4 & $\begin{array}{l}\text { Bakat seni } \\
\text { masyarakat }\end{array}$ & 0,637 \\
\hline & PSB5 & Kesenian khas desa & 0,557 \\
\hline
\end{tabular}

\begin{tabular}{|c|c|c|c|}
\hline \multirow{2}{*}{ Konsep } & \multicolumn{3}{|c|}{ Item Pengukur } \\
\hline & Kode & Deskripsi & $\rho$ \\
\hline \multirow{7}{*}{ 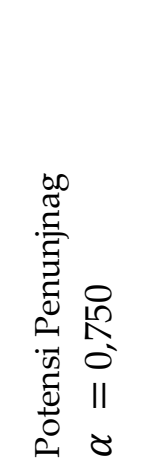 } & PP1 & Art stage & 0,324 \\
\hline & PP2 & Lapangan & 0,166 \\
\hline & PP3 & Rest area & 0,617 \\
\hline & PP4 & Kebersihan desa & 0,550 \\
\hline & PP5 & Fasilitas komunikasi & 0,587 \\
\hline & PP6 & Desa terjangkau & 0,701 \\
\hline & PP7 & $\begin{array}{l}\text { Kesiapan } \\
\text { masyarakat }\end{array}$ & 0,679 \\
\hline
\end{tabular}

Keterangan: Hasil analisis (2020)

Hasil analisis memperlihatkan pada setiap konsep terdapat item pengukur yang memiliki nilai $\rho<0.30$. Mencermati hal ini, analisis diulang dengan mengeliminasi item dengan $\rho$ terkecil. Hasil analisis akhir menunjukkan potensi sumber daya alam memiliki nilai reliabilitas 0,687 dengan item PA5 tereliminasi; 
potensi sumber daya sosial budaya memiliki nilai reliabilitas 0,786 dengan PSB1 dan PSB3 tereliminasi; dan fasilitas penunjang memiliki nilai reliabilitas 0,798 dengan PP2 tereliminasi.

\section{B. Karakteristik Sosio-Demografi Responden}

Seluruh responden merupakan penduduk desa yang telah berumur di atas 20 tahun atau telah berkeluarga dan telah berdiam di desa sekurang-kurangnya 10 tahun tanpa jeda. Pemeriksaan deskriptif data menunjukkan 7 dari 10 responden adalah responden perempuan dengan usia dominan berada pada kelompok umur 31 tahun ke atas (90 persen). Pada atribut pendidikan tertinggi yang ditamatkan, 75 persen responden berpendidikan SMA ke atas; 25 persen responden bahkan berpendidikan sarjana atau pascasarjana. Distribusi frekuensi pekerjaan dan kelompok pendapatan responden ditunjukkan pada gambar 4 .

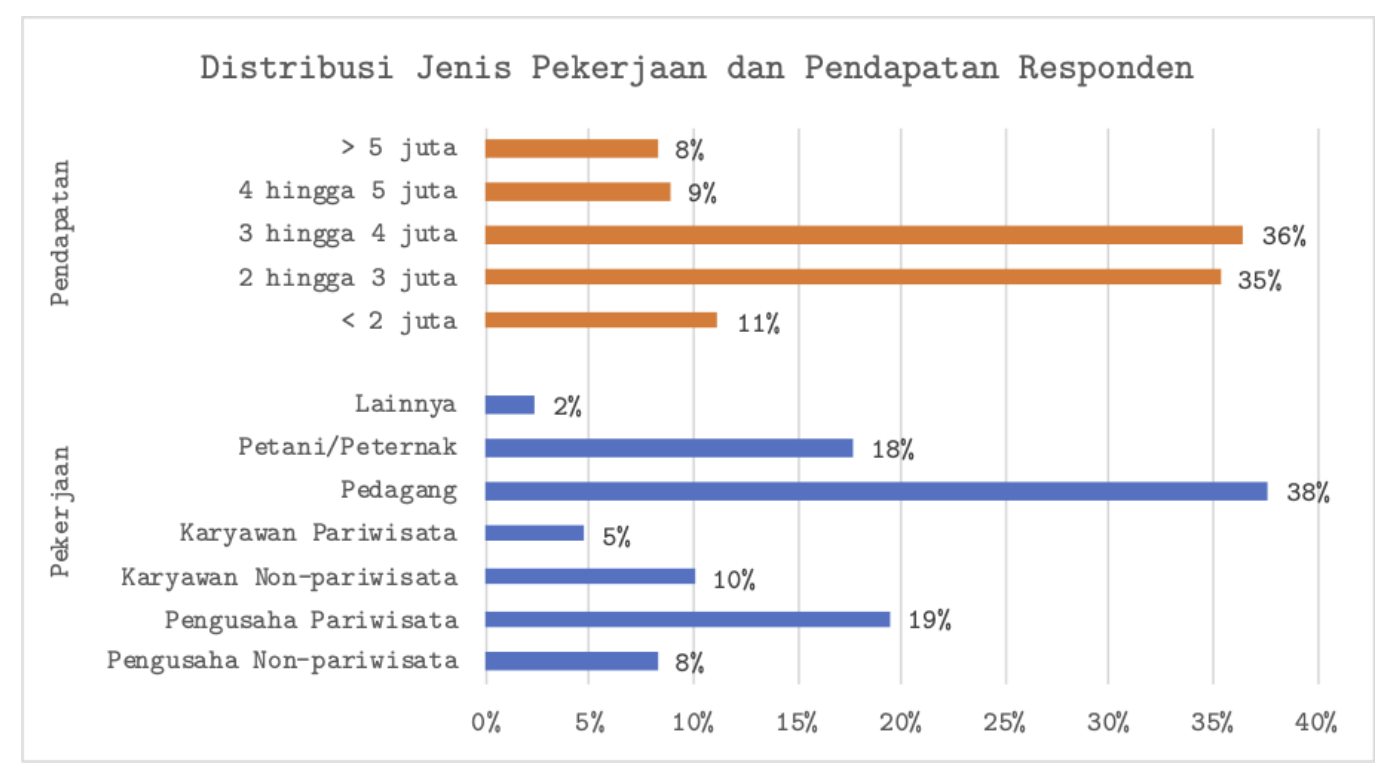

Gambar 4. Distribusi Frekuensi Jenis Pekerjaan dan Pendapatan Responden

Tanpa membedakan desa asal responden terlihat profesi pedagang, pengusaha pariwisata, dan petani atau peternak mendominasi (75 persen) jenis pekerjaan dari responden. Ditinjau dari total pendapatan per bulan, sebagian besar responden menyatakan berpenghasilan di atas 2 juta rupiah. Mencermati hasil analisis terhadap 
aspek sosio-demografi responden khususnya tingkat pendidikan, pendapatan per bulan, dan jenis pekerjaannya; persepsi mereka mengenai potensi desa berkembang sebagai DTW bisa dipercaya.

\section{Ekstraksi Informasi Potensi Desa}

Potensi dari 70 desa di Kabupaten Gianyar yang diukur melalui 13 item tersisa diekstraksi menggunakan Analisis Faktor (AF). AF dilakukan untuk setiap jenis dari potensi desa (alam, sosial budaya, dan fasilitas penunjang). Merujuk Hair et al. (2010) AF merupakan salah satu analisis pada kelompok multivariate statistics yang tergolong sebagai independence technique, teknik analisis yang tidak membedakan variabel bebas dengan variabel tak bebas. Terdapat sejumlah tahapan yang harus dilakukan dalam mengaplikasikan AF, yaitu:

1. Menghitung statistik Kaiser-Meyer-Olkin (KMO) dan statistik Bartlett $\chi^{2}$. Data layak diekstraksi bila statistik $\mathrm{KMO} \geq 0.50$ dan statistik Bartlett $\chi^{2}$ signifikan pada taraf uji yang dipilih;

2. Memeriksa nilai measure of sampling adequacy (MSA) dari setiap item. Item layak disertakan pada AF bila nilai MSA $\geq 0.50$;

3. Menentukan jumlah komponen yang diekstraksi. Pada tulisan ini jumlah komponen terekstraksi ditentukan oleh nilai eigen lebih besar dari 0,8;

4. Bila jumlah komponen $>1$, perotasian dilakukan menggunakan rotasi orthogonal untuk mempermudah interpretasinya; dan

5. Menginterpretasikan komponen yang terbentuk.

Mengikuti kelima tahapan di atas, informasi yang diperoleh melalui item-item pengukur ketiga konsep riset diekstraksi dengan hasil diringkas pada Tabel 3. 
Tabel 3. Ekstraksi Informasi Indikator Potensi Desa Menggunakan Analisis Faktor

\begin{tabular}{|c|c|c|c|c|c|c|}
\hline \multirow{2}{*}{ Konsep } & \multicolumn{4}{|c|}{ Item Pengukur } & \multicolumn{2}{|c|}{ Nilai Loading } \\
\hline & Kode & Deskripsi & MSA & $\begin{array}{l}\text { Komu- } \\
\text { nalitas }\end{array}$ & $\begin{array}{r}\text { Faktor } \\
\text { I }\end{array}$ & $\begin{array}{r}\text { Faktor } \\
\text { II }\end{array}$ \\
\hline \multirow[b]{2}{*}{ Potensi Alam } & PA1 & Panorama desa & 0,559 & 0,840 & 0,909 & 0,115 \\
\hline & PA4 & Keasrian lingkungan desa & 0,563 & 0,827 & 0,890 & 0,188 \\
\hline $\mathrm{KMO}=\quad 0,589$ & PA2 & Keunikan flora & 0,652 & 0,670 & 0,132 & 0,808 \\
\hline$\chi_{(6)}^{2}=137,820$ & PA3 & Keunikan fauna & 0,694 & 0,655 & 0,136 & 0,798 \\
\hline$=0,000$ & \multicolumn{4}{|c|}{ Nilai eigen } & 2,008 & 0,983 \\
\hline & \multicolumn{4}{|c|}{ Variansi terjelaskan (persen) } & 41,358 & 33,433 \\
\hline \multirow{2}{*}{$\begin{array}{l}\text { Potensi Sosial } \\
\text { Budaya }\end{array}$} & PB5 & Kesenian khas desa & 0,525 & 0,921 & 0,955 & 0,090 \\
\hline & PB4 & Bakat seni masyarakat & 0,523 & 0,914 & 0,935 & 0,198 \\
\hline \multirow{3}{*}{$\begin{array}{lr}\mathrm{KMO}= & 0,539 \\
\chi_{(3)}^{2} & =213,447 \\
p & =0,000\end{array}$} & PB2 & Pura sebagai daya tarik & 0,740 & 0,999 & 0,147 & 0,989 \\
\hline & \multicolumn{4}{|c|}{ Nilai eigen } & 1,990 & 0,844 \\
\hline & \multicolumn{4}{|c|}{ Variansi terjelaskan (persen) } & 60,303 & 34,162 \\
\hline \multirow{8}{*}{$\begin{array}{l}\text { Potensi } \\
\text { Penunjang } \\
\mathrm{KMO}=0,721 \\
\begin{array}{lr}\chi_{(15)}^{2}= & 457,400 \\
p \quad= & 0,000\end{array}\end{array}$} & PP6 & Aksesibilitas desa & 0,701 & 0,865 & 0,914 & 0,174 \\
\hline & PP5 & $\begin{array}{l}\text { Ketersediaan fasilitas } \\
\text { komunikasi }\end{array}$ & 0,758 & 0,836 & 0,909 & 0,098 \\
\hline & PP7 & Kesiapan masyarakat desa & 0,781 & 0,802 & 0,886 & 0,134 \\
\hline & PP3 & Ketersediaan rest area & 0,617 & 0,745 & 0,026 & 0,863 \\
\hline & PP4 & $\begin{array}{l}\text { Kebersihan di lingkungan } \\
\text { desa }\end{array}$ & 0,670 & 0,668 & 0,230 & 0,784 \\
\hline & PP1 & Ketersediaan art stage & 0,784 & 0,519 & 0,114 & 0,711 \\
\hline & \multicolumn{4}{|c|}{ Nilai eigen } & 2,932 & 1,504 \\
\hline & \multicolumn{4}{|c|}{ Variansi terjelaskan (persen) } & 41,870 & 32,065 \\
\hline
\end{tabular}

Keterangan: Hasil analisis (2020)

Ekstraksi informasi yang dilakukan menggunakan AF memperlihatkan ketiga matriks data layak diekstraksi mencermati nilai KMO dan statistik Bartlett melebihi nilai ambang bawah yang dipersyaratkan. Pemeriksaan nilai MSA masing-masing item juga menunjukkan item-item pengukur layak diekstraksi. Menggunakan kriteria nilai eigen dalam menentukan jumlah faktor yang diekstraksi, setiap konsep riset terekstraksi menjadi 2 komponen, Faktor I dan Faktor II, yang dirotasi orthogonal menggunakan metode varimax untuk memperjelas interpretasi faktor. 
Pada konsep potensi sumber daya alam, keempat item terekstraksi menjadi 2 faktor. Faktor I yang dikomposisikan oleh PA1 dan PA4 merupakan faktor Suasana Desa dan Faktor II dikomposisikan oleh PA2 dan PA3 merupakan faktor Keunikan Flora \& Fauna Desa. Kedua faktor mampu menjelaskan total keragaman data sebesar 74,8 persen. Total keragaman yang dijelaskan faktor Suasana Desa dua kali lebih besar dibandingkan dengan yang terjelaskan faktor Flora \& Fauna Desa. Fakta empiris ini menunjukkan persepsi masyarakat mengenai potensi alam di desanya sebagai DTW lebih terefleksikan pada suasana pedesaan yang damai dilengkapi dengan panorama atau saujana yang memesona.

Pada konsep potensi sosial budaya masyarakat desa, ketiga item pengukur juga terekstraksi menjadi 2 faktor yaitu faktor Seni di Desa dan Daya Tarik Pura, masing-masing dengan total keragaman terjelaskan 60,3 persen dan 34,1 persen. Bila kedua faktor dikomparasikan maka masyarakat desa lebih memilih mengedepankan potensi seni dibandingkan memilih pura sebagai daya tarik kunjungan wisatawan. Total keragaman pada matriks data yang terekstraksi kedua faktor ini adalah 94,5 persen.

Konsep terakhir, faktor penunjang yang diukur melalui 6 item, juga terekstraksi menjadi 2 faktor. Faktor I yang disusun oleh PP6, PP5, dan PP7 dengan nilai variansi terjelaskan 41,9 persen merupakan Aksesibilitas Desa. Faktor kedua yang disusun oleh PP3, PP4, dan PP1 dengan variansi terjelaskan 32,1 persen merupakan faktor Kenyamanan Berwisata dengan adanya rest area dan kebersihan lingkungan desa. 


\section{Klasterisasi Desa Berdasarkan Potensi Desa}

Klasterisasi (clustering) merupakan salah satu teknik analisis statistika yang lazim digunakan pada data mining. Teknik klasterisasi bertujuan mengelompokkan $n$ objek ke dalam $x$ kelas, $x \ll n$, sedemikian rupa sehingga variansi intrakelas minimum dan variansi antarkelas maksimum (Giordani et al., 2020; Wu, 2012). Pada ranah Sains Data, klasterisasi tergolong teknik pembelajaran terawasi (supervised learning) di mana jumlah klaster ditentukan sebelum klasterisasi dilakukan. Terdapat sejumlah teknik yang bisa digunakan untuk membentuk klaster pada pembelajaran terawasi, di mana teknik K-means Clustering dianggap teknik terpopuler dan tersederhana. Tulisan ini menggunakan K-means Clustering untuk mengklasifikasikan 70 desa di Kabupaten Gianyar menggunakan 6 atribut potensi desa yang diperoleh pada Analisis Faktor dengan jumlah klaster ditetapkan 3 klaster seperti diuraikan sebelumnya. Tabel 4 menunjukkan centroid (pusat luasan) dari setiap klaster.

Tabel 4. Centroid dari Masing-masing Klaster

\begin{tabular}{lrrr}
\hline \multirow{2}{*}{ Atribut } & \multicolumn{3}{c}{ Klaster Desa } \\
\cline { 2 - 4 } & $\begin{array}{r}\text { I. Telah } \\
\text { Berkembang }\end{array}$ & $\begin{array}{r}\text { II. Sedang } \\
\text { Berkembang }\end{array}$ & $\begin{array}{r}\text { III. Belum } \\
\text { Berkembang }\end{array}$ \\
\hline Suasana Desa & 0,307 & $\mathbf{0 , 8 4 2}$ & $-0,694$ \\
\hline Keunikan Flora \& Fauna & $\mathbf{1 , 1 4 6}$ & $-0,328$ & $-0,225$ \\
\hline Kesenian di Desa & $\mathbf{0 , 6 8 8}$ & 0,123 & $-0,585$ \\
\hline Daya Tarik Pura & 0,041 & $\mathbf{0 , 1 0 2}$ & $-0,094$ \\
\hline Aksesibilitas Desa & 0,238 & $-1,079$ & $\mathbf{0 , 3 5 8}$ \\
\hline Kenyamanan Berwisata & $\mathbf{1 , 0 1 6}$ & 0,066 & $-0,303$ \\
\hline
\end{tabular}

Keterangan: Hasil analisis (2020)

Mencermati centroid dari setiap klaster, terlihat klaster I unggul pada 3 atribut penting dari daya tarik yaitu keunikan flora dan fauna, kenyamanan berwisata, dan potensi seni masyarakat desa. Klaster II unggul pada potensi suasana desa serta daya tarik pura, dan klaster III hanya unggul pada potensi aksessibilitas. Pada klaster I 
tidak ditemui centroid dengan nilai negatif seperti halnya pada klaster II (2 atribut) dan klaster III (5 atribut) yang mengindikasikan 'kesenjangan' kemenarikan antardesa yang berbeda klaster. Hasil analisis juga menunjukkan jumlah desa yang tergolong anggota klaster I, II, dan III masing-masing berjumlah 13 desa, 24 desa, dan 33 desa (lihat Tabel 5).

Tabel 5. Desa-desa Anggota dari Setiap Klaster

\begin{tabular}{|c|c|c|c|c|c|}
\hline \multirow{2}{*}{$\begin{array}{l}\text { Klaster I } \\
\text { Saba }\end{array}$} & \multicolumn{2}{|c|}{ Klaster II } & \multicolumn{3}{|c|}{ Klaster III } \\
\hline & Belega & $\begin{array}{l}\text { Pejeng } \\
\text { Kangin }\end{array}$ & Bedulu & Bakbakan & Puhu \\
\hline Batuan & Bona & $\begin{array}{l}\text { Pejeng } \\
\text { Kawan }\end{array}$ & Blahbatuh & Bitera & Sanding \\
\hline Batubulan & Buruan & $\begin{array}{l}\text { Pejeng } \\
\text { Kelod }\end{array}$ & Medahan & Gianyar & Petak Kaja \\
\hline Kemenuh & Keramas & Kedisan & $\begin{array}{l}\text { Batuan } \\
\text { Kaler }\end{array}$ & Lebih & Pupuan \\
\hline Singapadu & Pering & Keliki & $\begin{array}{l}\text { Batubulan } \\
\text { Kangin }\end{array}$ & Samplangan & Bresela \\
\hline Serongga & $\begin{array}{l}\text { Singapadu } \\
\text { Tengah }\end{array}$ & Kenderan & Celuk & Beng & Bukian \\
\hline Tampaksiring & Petak & Sebatu & Guwang & Siangan & Kelusa \\
\hline Taro & Sidan & Buahan & Ketewel & Sumita & Melinggih \\
\hline Tegallalang & Tulikup & Buahan Kaja & $\begin{array}{l}\text { Singapadu } \\
\text { Kaler }\end{array}$ & Suwat & $\begin{array}{l}\text { Melinggih } \\
\text { Kelod }\end{array}$ \\
\hline Kerta & Pejeng & Manukaya & Sukawati & Tegal Tugu & Kedewatan \\
\hline Petulu & Pejeng Kaja & Mas & Abianbase & Temesi & Lodtunduh \\
\hline Singakerta & Peliatan & Sayan & & & \\
\hline Ubud & & & & & \\
\hline
\end{tabular}

Keterangan: Hasil analisis (2020)

\section{E. Diskusi}

Klaster I yang beranggotakan 13 desa yang potensi wisatanya dipersepsikan telah berkembang, dimotori oleh Kelurahan Ubud lokasi dari Mandala Suci Wanara Wana (The Monkey Forest) menjustifikasi atribut keunikan flora dan fauna sebagai atribut dominan pada klaster ini. Tersedianya daya tarik buatan seperti Taman Burung dan Rimba Reptil (Bali Bird Park) dan Bali Zoo Park di Desa Singapadu, Wisata 
Gajah di Desa Taro, serta Bali Safari and Marine Park di Desa Serongga juga menjustifikasi dominansi atribut keunikan flora dan fauna. Pun Desa Petulu yang terkenal dengan burung kokokan tergabung ke dalam klaster ini.

Potensi kesenian pun merupakan atribut lain yang membedakan desa anggota dari klaster ini dengan desa anggota klaster lainnya. Desa Batubulan merupakan desa yang menjadi perintis pertunjukan barong kepada wisatawan. Demikian pula halnya dengan Desa Batuan dan Desa Singapadu yang terkenal dengan berbagai ekspresi seni (lukis, pahat, dan patung) menunjukkan kontribusi dari atribut seni masyarakat dalam mendukung desanya sebagai DTW.

Memperhatikan peran potensi seni di kabupaten ini, khususnya di desa-desa anggota klaster I, telah menjadi salah satu atribut dominan pada pengembangan kepariwisataan daerah maka bisa diyakini kepariwisataan di Kabupaten Gianyar telah sejalan dengan amanat Peraturan Daerah (PERDA) Provinsi Bali Nomor 2 Tahun 2012 tentang Kepariwisataan Budaya Bali, serta dipertegas pada pasal 1 ayat (12) PERDA Provinsi Bali Nomor 5 Tahun 2020 tentang Standar Penyelenggaraan Kepariwisataan Budaya Bali yang menyatakan "Kepariwisataan Budaya Bali adalah kepariwisataan Bali yang berlandaskan kepada Kebudayaan Bali yang dijiwai oleh filosofi Tri Hita Karana yang bersumber dari nilai-nilai budaya dan kearifan lokal Sad Kerthi serta berbasis taksu Bali.".

Pada klaster II yang beranggotakan 24 desa, atribut dominannya adalah suasana desa meliputi saujana dan lingkungan desa yang masih asri. Salah satu penggerak pada klaster ini adalah Desa Manukaya dengan keberadaaan Pura Tirta Empul serta Desa Sebatu yang juga menjadi favorit kunjungan wisatawan. Mencermati atribut aksesibilitas desa anggota klaster ini bernilai negatif serta terkecil bila dibandingkan dengan nilai pada dua klaster lainnya, sangatlah penting akses menuju dan antardesa dalam klaster ditingkatkan. 
Klaster III merupakan klaster dengan anggota terbanyak, 33 desa. Selain atribut aksesibilitas, centroid lima atribut lainnya dari klaster ini bernilai negatif. Sebagian desa ini, seperti Kelurahan Gianyar dan Sukawati, merupakan pusat-pusat aktivitas perekonomian masyarakat di Kabupaten Gianyar yang menyebabkan atribut suasana desa memiliki centroid bernilai negatif. Jika klaster ini akan dibangun sebagai DTW, sangat penting untuk menentukan jenis atraksi yang ditawarkan. Hal ini tidak terlepas dari atribut aksesibilitas yang bernilai positif. Mengutip AlKahtani et al. (2015) yang berpendapat bila aksesibilitas merupakan keterjangkauan destinasi oleh wisatawan, maka semakin baik aksesibilitas destinasi seyogyanya semakin besar peluang dikunjungi wisatawan. Dalam hal ini, atribut aksesibilitas merupakan modal bagi desa-desa dalam klaster ini untuk mulai mengembangkan desanya sebagai DTW dengan mencermati kekurangan yang dimilikinya dibandingkan dengan desa-desa pada klaster lainnya.

\section{Simpulan dan Limitasi Studi}

\section{A. Simpulan}

Pengembangan desa-desa di Kabupaten Gianyar sebagai daya tarik wisata seyogyanya dilakukan agar tidak terjadi kompetisi yang tidak sehat antardesa. Hal ini dapat dilakukan dengan memetakan potensi unik dari setiap desa. Klasterisasi 70 desa di Kabupaten Gianyar yang dilakukan melalui studi persepsi masyarakat desa tentang potensi desa untuk berkembang sebagai daya tarik, menyimpulkan:

1. Terdapat 6 atribut potensi desa yang dapat dimanfaatkan untuk mengembangkan desa-desa Kabupaten Gianyar sebagai daya tarik wisata. Keenam atribut ini adalah: (a) Suasana desa; (b) Keunikan flora \& fauna; (c) kesenian masyarakat desa; (d) Eksistensi pura sebagai daya tarik; (e) Aksesibilitas; dan (f) Kenyamanan berwisata; 
2. Terbentuk tiga klaster desa berdasarkan potensinya yaitu klaster desa yang telah berkembang sebagai DTW beranggotakan 13 desa (Klaster I), klaster desa yang sedang berkembang beranggotakan 24 desa (Klaster II), dan klaster desa yang belum berkembang beranggotakan 33 desa (Klaster III); dan

3. Klaster I memiliki keunggulan pada keunikan flora \& fauna, kenyamanan, dan potensi seni masyarakat desa. Klaster II unggul pada atribut suasana desa serta pura sebagai daya tarik, sedangkan klaster III unggul pada aksesibilitas menuju dan antardesa dalam klaster yang sama.

\section{B. Limitasi Studi}

Studi untuk mengklasterisasi desa-desa di Kabupaten Gianyar berdasarkan potensi desa sebagai daya tarik wisata dilakukan hanya dengan mengukur persepsi masyarakat desa. Persepsi masyarakat memang merupakan hal yang sangat penting dalam perencanaan destinasi tetapi belum cukup untuk memotret pendapat lima pemangku keperntingan lainnya, yaitu: akademisi, dunia usaha (bisnis), pemerintah, mass-media, dan wisatawan. Terkait dengan keterbatasan ini, studi lain sangat layak dilakukan sehingga pendapat seluruh pemangku kepentingan terakomodir. Diskusi terpumpun (focus group discussion/FGD) sangat dianjurkan agar perencanaan dan/atau pengembangan desa-desa wisata di Kabupaten Gianyar bersifat menyeluruh.

\section{Daftar Pustaka}

AlKahtani, S. J. H., Xia, J., Veenendaaland, B., Caulfield, C., \& Hughes, M. (2015). Building a conceptual framework for determining individual differences of accessibility to tourist attractions. Tourism Management Perspectives, 16, 28-42. https://doi.org/10.1016/j.tmp.2015.05.002

BPS Kabupaten Gianyar. (2020). Kabupaten Gianyar Dalam Angka 2020. In Kabupaten Gianyar dalam Angka.

Creswell, J. W. (2009). Research Design: Qualitative, Quantitative, and Mixed Methods Approaches (3rd ed.). SAGE Publications. Inc. 
Dinas Pariwisata Provinsi Bali. (2020). Buku Statistik Pariwisata Bali Tahun 2019. Dinas Pariwisata Provinsi Bali.

Giordani, P., Ferraro, M. B., \& Martella, F. (2020). An Introduction to Clustering with $R$ (A. Okada (ed.); Vol. 3, Issue June). Springer Science+Business Media, LLC. https://doi.org/10.1007/978-981-13-0553-5

Hair, J. F., Black, W. C., Babin, B. J., \& Anderson, R. E. (2010). Multivariate Data Analysis with Readings (7th ed.). Prentice-Hall, Inc.

Kencana, E. N., Darmayanti, T., \& Jayanegara, K. (2019). Does motivation have meaning for loyalties? Empirical study from cultural destinations in Bali. Journal of Physics: Conference Series, 1321(2). https://doi.org/10.1088/1742$6596 / 1321 / 2 / 022084$

Nunnally, J. C. (1975). Psychometric Theory. 25 Years Ago and Now. Educational Researcher, 4(10), 7-14+19-21.

$\mathrm{Wu}$, J. (2012). Advances in K-means Clustering: A Data Mining Thinking. https://doi.org/10.1007/978-3-642-29807-3

\section{Profil Penulis}

Eka N Kencana adalah peneliti di Pusat Unggulan Pariwisata - Universitas Udayana. Sebagai dosen tetap di Program Studi Matematika - Fakultas MIPA UNUD, ia aktif melakukan riset pada ranah sosial humaniora khususnya mengamati fenomena kepariwisataan dari perspektif kuantitatif._Profil riset dan publikasi yang telah dilakukannya bisa dilihat di:

\section{https://udayananetworking.unud.ac.id/lecturer/2293-eka-n-kencana}

Putu Suciptawati adalah dosen tetap di Program Studi Matematika - Fakultas MIPA UNUD. Sebagai salah satu anggota Kelompok Bidang Keahlian Statistika di PS Matematika, topik risetnya lebih banyak berada pada ranah Advance Regression dan Statistical Modeling. 
Trisna Darmayanti adalah dosen tetap di Program Studi Teknologi Pangan - Fakultas Teknologi Pangan ITP. Mengemukanya culinary tourism, membuatnya tertarik untuk meneliti kuliner tradisional Bali dari perspektif pariwisata.

Mirah P Handayani adalah alumni Bidang Keahlian Statistika di Program Studi Matematika - Fakultas MIPA UNUD. 